\title{
Carcinoid myopathy and treatment with cyproheptadine (Periactin)
}

\author{
ELLIOT M. BERRY' ${ }^{1}$, CAROLINE MAUNDER, AND MARIE WILSON \\ From the Royal Postgraduate Medical School, Hammersmith Hospital, London
}

SUMMARY A case of the carcinoid syndrome associated with a proximal myopathy is reported. Histology showed advanced atrophy of type II muscle fibres but no inflammation. Perinuclear acid phosphatase was increased. Electron microscopy revealed persistence of the Z-line until the muscle fibre had been severely disrupted. Similar lesions have been observed in the hereditary muscular dystrophy in mice, and also in these animals and in rats when injected with 5-hydroxytryptamine (5-HT).

Treatment with cyproheptadine caused a documented response in the patient's debilitating diarrhoea and also produced symptomatic improvement in her muscular power. We suggest that the myopathy is due to circulating 5-HT or is a non-metastatic complication of the carcinoid tumour.

Comprehensive reviews of the carcinoid syndrome (Grahame-Smith, 1972) and of carcinomatous neuropathies (Wilkinson, Croft, and Urich, 1967) do not mention the existence of a specific carcinoid myopathy, and only one case of this association has been recorded (Green, Joynt, and Van Allen, 1964). We report here a second case of a myopathy associated with the carcinoid syndrome, including detailed histological studies and a documented response of the patient's diarrhoea to treatment with cyproheptadine.

\section{Case Report}

A 47-year-old housewife complained of flushing attacks in 1960. These were attributed to the menopause but continued progressively over the following eight years. She then began having diarrhoea and in 1970 noted a mass under the right costal margin. Laparotomy revealed multiple white deposits throughout the liver and gallbladder. Histology was of an argentaffin carcinoma and the primary was considered to be fromthe gall bladder. Twenty-fourhour urinary excretion of 5-hydroxyindoleacetic acid (5-HIAA) varied between 65 and $385 \mathrm{mg}$ (normal range 3-17 $\mathrm{mg}$ ). Over the next two years the patient developed pulmonary stenosis, whilst the

${ }^{1}$ Present address: Department of Medicine B, PO Box 499, Hadassah University Hospital, Jerusalem, Israel.

Received for publication 6 September 1973. diarrhoea and flushing attacks became more severe. She was treated with a number of drugs, including codeine phosphate, phenoxybenzamine, methysergide, and two courses of streptozotocin, with little permanent benefit. (These aspects of her history have been reported elsewhere by Iweze, Owen-Smith, and Polak, 1972.) In 1972 she complained of severe limb weakness and she was re-admitted to the metabolic unit of the Hammersmith Hospital for further investigation and treatment.

On examination the patient was listless and apathetic; the muscles were not tender. There was proximal limb and girdle weakness with focal wasting of the shoulder muscles. Reflexes, plantar responses, and sensation were all normal.

\section{LA BORATORY INVESTIGATIONS}

Haemoglobin $11.7 \mathrm{~g} / 100 \mathrm{ml}$, normal white count; serum urea, electrolytes, and proteins, and electrophoretic strip, normal. Serum enzymes varied between the values shown below (normal ranges in brackets): glutamic oxaloacetic transaminase 250-23 international units (iu)/litre (2-20); alkaline phosphatase 56-14 King Armstrong units (3-13); 5' nucleotidase 18-7 iu (2-11); isocitrate dehydrogenase 47-14 iu (3-8); creatine kinase 2 iu (less than 50). Serum bilirubin $0.3 \mathrm{mg} / 100 \mathrm{ml}(0 \cdot 1-0 \cdot 8)$; serum albumin $3.3 \mathrm{~g} / 100 \mathrm{ml}$ (3.6-5.2); plasma calcium $9.0 \mathrm{mg} / 100$ $\mathrm{ml}(8 \cdot 9-10 \cdot 5)$; plasma inorganic phosphorus 4.2 $\mathrm{mg} / 100 \mathrm{ml}(2 \cdot 1-4 \cdot 5) ;$ protein-bound iodine $4 \cdot 4 \mu \mathrm{g} / 100$ 


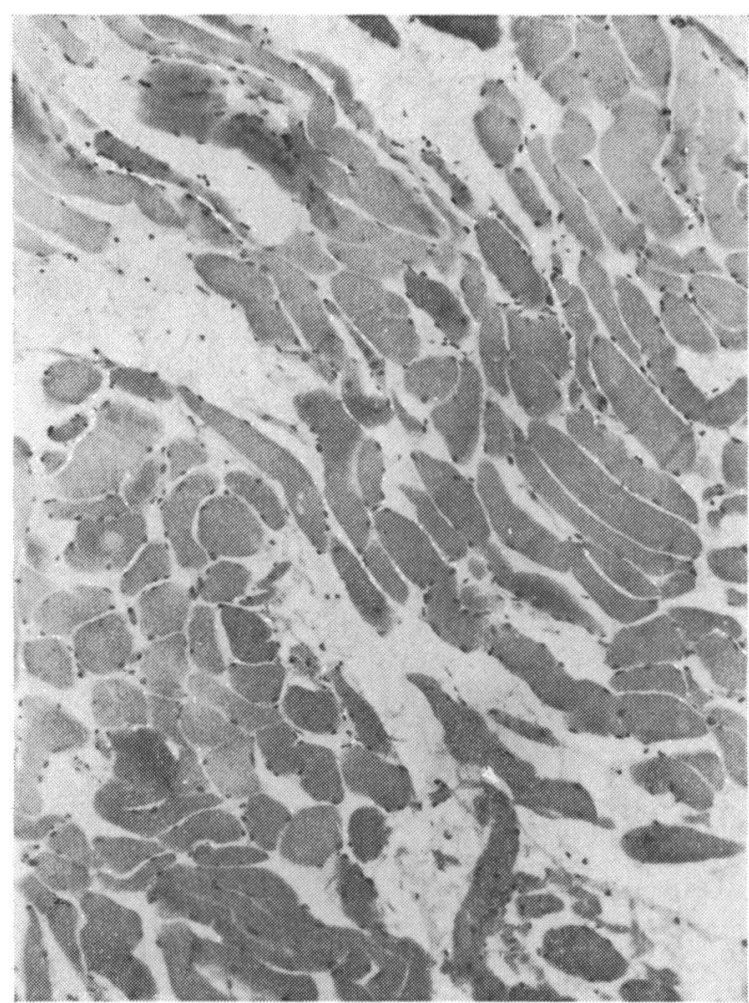

Fig 1

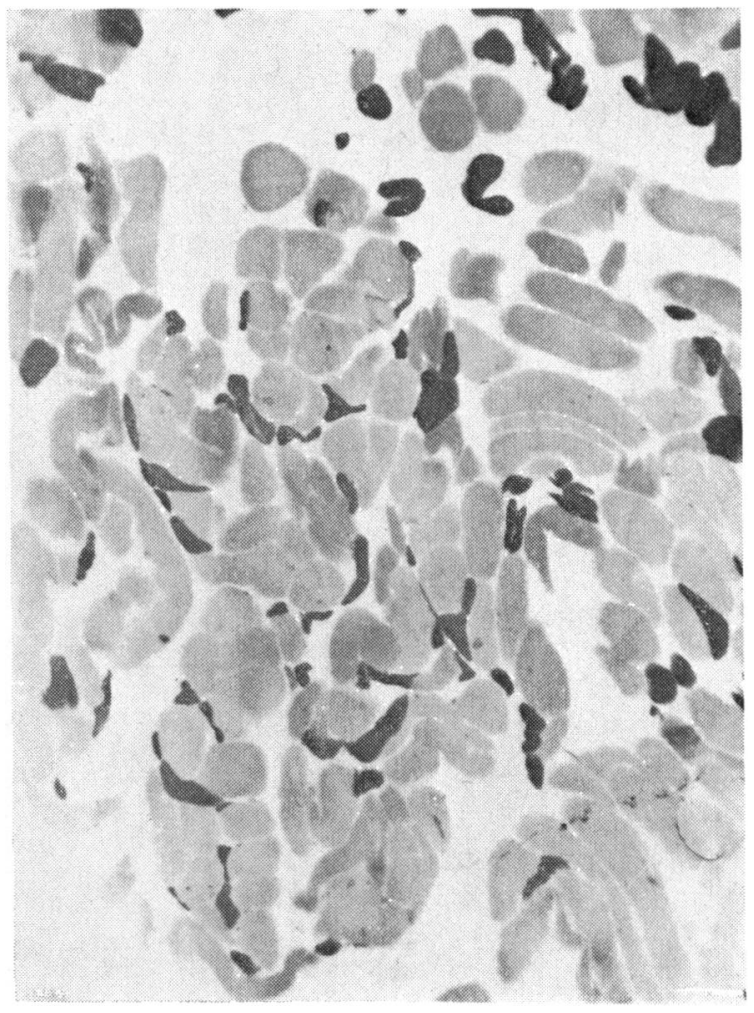

Fig 2

Fig 1 Cryostat section $(8 \mu)$ showing atrophy and fibre necrosis. Haematoxylin and eosin $\times 100$.

Fig 2 Cryostat section $(8 \mu)$ showing atrophy of darkly staining type II fibres. Myosin ATPase $\times 100$.

$\mathrm{ml}(3 \cdot 7-8 \cdot 1)$; blood 5-hydroxytryptamine (5-HT) $2.0 \mu \mathrm{g} / \mathrm{ml}(0 \cdot 037-0 \cdot 280)$. On urine chromatography no 5-HT or 5-hydroxytryptophan was detected; urine 5-HIAA $65-1155 \mathrm{mg} / 24$ hour (3-17); urine free cortisol $22 \mu \mathrm{g} / 24$ hour (less than 100). Faecal fat excretion $5.4 \mathrm{~g} /$ day (less than 6 ). Electromyogram normal.

\section{HISTOLOGY}

Biopsy of the right infraspinatus muscle revealed a number of histological and histochemical abnormalities. There were more central nuclei than normal, and some fibre necrosis was evident (fig 1). The type II fibres showed an advanced degree of atrophy (fig 2) and perinuclear acid phosphatase was increased. No inflammation was visible. Electron microscopical examination showed degeneration and splitting of the myofibrils in several fibres (fig 3) but the $Z$ line persisted until the fibre had become severely disrupted. There was no alteration in the number of mitochondria but some appeared swollen. There was also enlargement of the sarcoplasmic reticulum in some fibres.

TREATMENT AND PROGRESS

The effect of treatment on this patient's diarrhoea is shown in figure 4. Parachlorophenylalanine in doses up to $4 \mathrm{~g}$ day was tried without benefit. However, adding cyproheptadine in a dose of $16-32 \mathrm{mg} /$ day, controlled the diarrhoea, and improved affect and muscle power (though biopsy was not repeated to verify this). The patient, previously confined to bed wearing loose clothing because of faecal soiling, was able to leave hospital and enjoy limited social activities. The frequency of the diarrhoea fell from 17 to about five times/day. There was no change in urinary excretion of 5-HIAA. Parachlorophenylalanine was discontinued after two weeks and the patient was discharged on cyproheptadine alone. Improvement in control of her diarrhoea has been maintained for over 10 months. Varying the timing of the drug dosage has abolished nocturnal faecal 


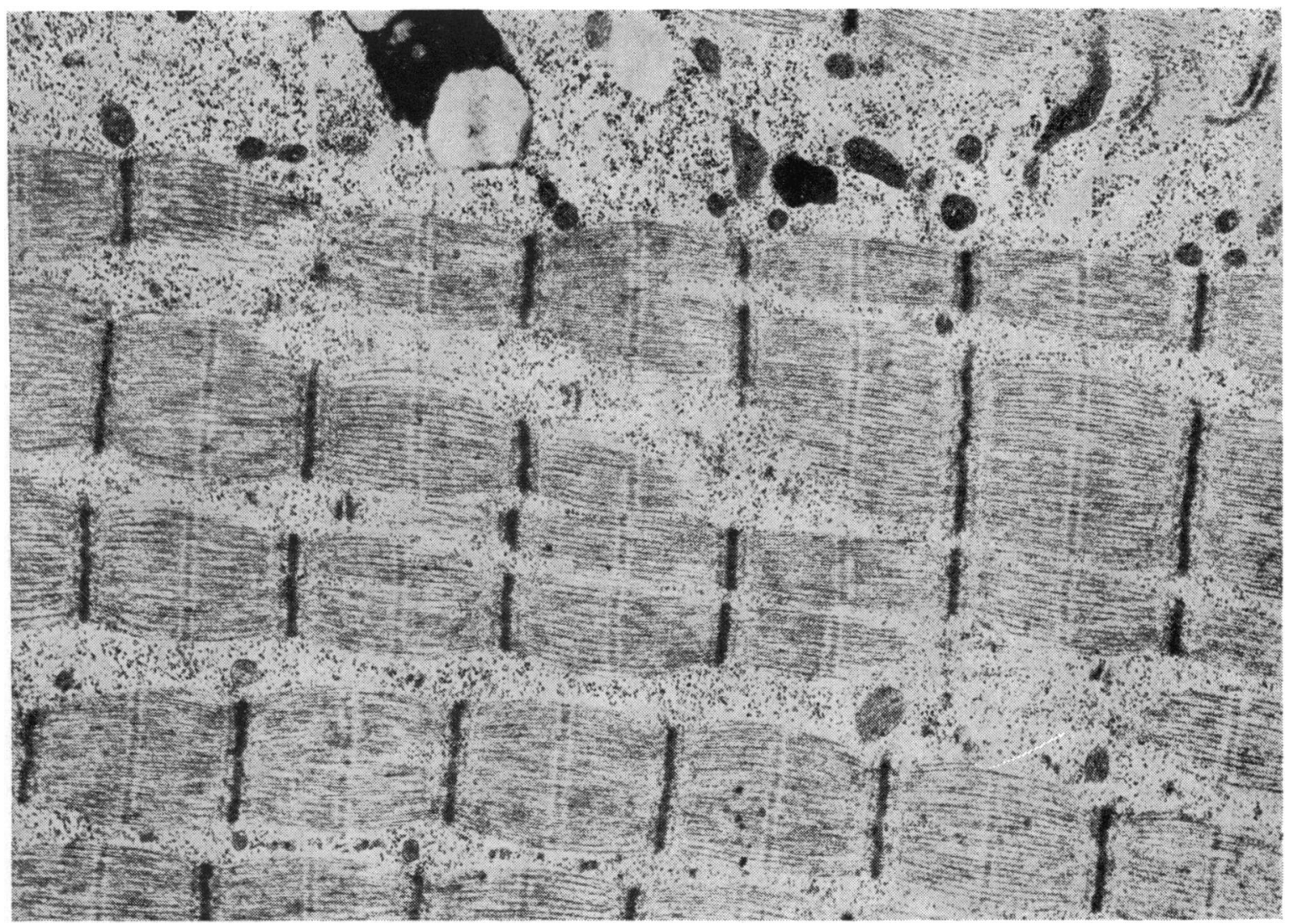

Fig 3

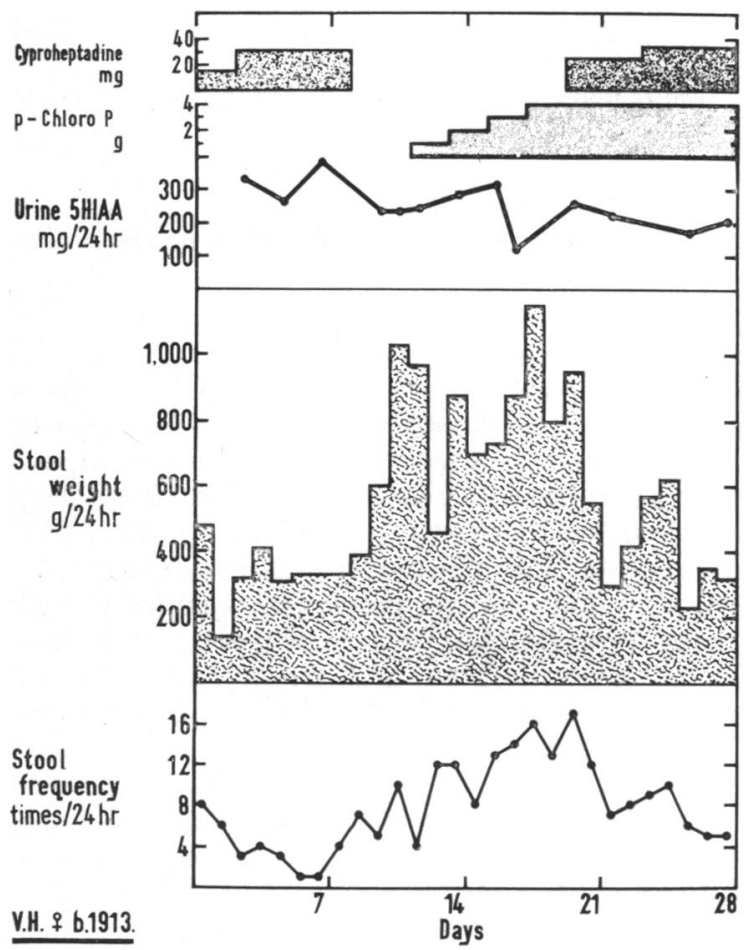

Fig 3 Electron micrograph showing degeneration and splitting of the myofibrils preceding disruption of the Zline. Counterstain uranyl acetate and lead citrate $\times 30000$

Fig 4 Variation in urinary 5-HIAA excretion, stool frequency, and wet weight (normal 100-200 g/24 hour) on treatment with cyproheptadine and p-chloro p (parachlorophenylalanine).

Fig 4 
incontinence. At present the patient is taking $16 \mathrm{mg}$ of cyproheptadine at night and $4 \mathrm{mg}$ once or twice during the day. Stool frequency varies between two and five times/day. The patient feels symptomatically stronger.

\section{Discussion}

The female patient described by Green et al (1964) developed neuromuscular symptoms three years after removal of a carcinoid tumour of the ileum. She had wasting and weakness of the distal musculature. Some muscles were tender on squeezing and there were also fasciculations in the hands and shoulders. Creatinekinase levels were not measured. There were subjective paraesthesiae in the hands and feet but no objective sensory deficit. Unlike the findings in our patient, in whom weakness was proximal and tenderness absent, the electromyogram was abnormal, with polyphasic potentials. Histology of the left sacrospinalis muscle showed chronic inflammation and some areas of hyperplastic nuclear proliferation. The authors considered the changes consistent with a neuromyopathy. However, inflammation is rarely associated with a neuropathy and the abnormalities described more closely resemble a myopathy. O'Steen, Barnard, and Yates (1967) have shown that morphological changes can be induced in skeletal muscle of mice by intraperitoneal injections of 5-HT. Some of these alterations are similar to those in the case reported here. Myofibrillar degeneration preceding $\mathbf{Z}$ line changes resembles the course of degeneration in hereditary muscular dystrophy (Ross, Pappas, and Harman, 1960). Mendell, Engel, and Derrer (1972) have shown that aortic ligature in rats in conjunction with $5-\mathrm{HT}$ injections $(20-25 \mu \mathrm{g} / \mathrm{g})$ can produce serum enzyme changes similar to those found in Duchenne muscular dystrophy. In view of this evidence, we believe that the myopathy in our case either was a non-metastatic complication of the carcinoid tumour or was caused directly by circulating 5-HT.

According to Vane (1969), if 5-HT is released from the intestine about $65 \%$ will be removed by the liver and more than $95 \%$ of that remaining will be removed by the lungs. Thus the amount reaching the arterial circulation will be reduced to less than $1 \%$ of that released. Free amine is also taken up by platelets (Stacey, 1961) but is not rapidly inactivated since the half-life is thought to be one to two minutes (Thomas and Vane, 1967). In our patient these protective mechanisms are presumably saturated and hence the 5-HT may damage peripheral tissues, including muscle.

Treatment with drugs was not implicated, since the myopathy began and continued when the patient was not taking any new preparations. Streptozotocin administration was discontinued one year before the onset of her symptoms, and, although this drug causes toxic degeneration of the islets of Langerhans, it is not known to have deleterious effects on muscle cells. There was no clinical or biochemical evidence of hypokalaemia, thyrotoxicosis, or ectopic hormone production of ACTH.

The muscle weakness in our patient was probably aggravated by the severe diarrhoea and poor general nutrition. The muscle wasting in cachexia, however, can scarcely be regarded as myopathic (McArdle, 1969).

There was no evidence of fat malabsorption nor of osteomalacia, apart from the intermittently raised alkaline phosphatase levels. These, together with the abnormal 5'-nucleotidase values, were considered related to the known hepatic metastases. However, Smith and Stern (1967) found that osteomalacia may present with proximal muscle weakness. Of 20 patients who had osteomalacia secondary to gastrointestinal disease, 11 had a myopathy and of these $10(91 \%)$ had steatorrhoea. Although the clinical features of the myopathy of our case were similar to their findings, their histology data were inconclusive. Two biopsies were taken: one was normal and the other showed a slight excess of fat in the muscle bundles and occasional clumping of sarcolemmal nuclei.

The case also illustrates the clinical management of diarrhoea in the carcinoid syndrome. Unlike the findings of Shani and Sheba (1970), parachlorophenylalanine was of no benefit. This compound prevents the synthesis of 5-HT by inhibiting the hydroxylation of tryptophan to 5-hydroxytryptophan. Cyproheptadine is thought to block the cellular site of action of 5-HT. Vroom, Brown, Dempsey, and Richardson Hill (1962) reported the beneficial effects of cyproheptadine, using an optimal dose of $80 \mathrm{mg} /$ day, in controlling diarrhoea and improving well being. The reason for the variation in patients' responses is not known.

The incidence of myopathy in the carcinoid syndrome may be greater than these isolated reports suggest. It may be easily missed in patients confined to bed, since any weakness may be attributed to the general condition (Wilkinson et al, 1967). Treatment is difficult ; an excellent clinical response to cyproheptadine has been found but this may be due to the effects on the central nervous system. Control of the diarrhoea would improve general wellbeing and strength without necessarily reversing the muscle pathology. The drug is related to the phenothiazine-type antih istamines (Stone, Wenger, Ludden, Stavorski, and Ross, 1961) and is also used as an appetite stimulant. 
We thank Dr G. R. Thompson for his helpful advice, Professor M. Sandler (Queen Charlotte's Maternity Hospital) for the 5-HT and 5-HIAA measurements, and the sister and staff of the metabolic unit ward and laboratory for data collection. Miss E. Cripps was both patient and prompt in typing the manuscript.

C.M. is in receipt of a grant from the Muscular Dystrophy Group of Great Britain.

Requests for reprints to E.M.B.

\section{References}

Grahame-Smith, D. G. (1972). The Carcinoid Syndrome. Heinemann, London.

Green, D., Joynt, R. J., and Van Allen, M. W. (1964). Neuromyopathy associated with a malignant carcinoid tumor. Arch. intern. Med., 114, 494-496.

Iweze, F. I., Owen-Smith, M., and Polak, J. (1972). Carcinoid syndrome treated with streptozotocin. Proc. roy. Soc. Med. 65, 164-165.

McArdle, B. (1969). In Disorders of Voluntary Muscle, 2nd ed., edited by J. N. Walton, p. 623. Churchill, London.

Mendell, J. R., Engel, W. K., and Derrer, E. C. (1972). Increased plasma enzyme concentrations in rats with functional ischaemia of muscle provide a possible model of Duchenne muscular dystrophy. Nature (Lond.), 239, 522-524.

O'Steen, W. K., Barnard, J. L. Jr., and Yates, R. D. (1967). Morphologic changes in skeletal muscle induced by serotonin treatment; a light- and electron-microscopic study. Exp. molec. Path., 7, 145-155.

Ross, M. H., Pappas, G. D., and Harman, P. J. (1960). Alterations in muscle fine structure in hereditary muscle dystrophy of mice. Lab. Invest., 9, 388-403.

Shani, M., and Sheba, C. (1970). Parachlorophenylalanine treatment in carcinoid syndrome. Brit. med. J., 4, 784-785.

Smith, R., and Stern G. (1967). Myopathy, osteomalacia and hyperparathyroidism. Brain, 90, 593-602.

Stacey, R. S. (1961). Uptake of 5-hydroxytryptamine by platelets. Brit. J. Pharmacol. Chemother., 16, 284-295.

Stone, C. A., Wenger, H. C., Ludden, C. T., Stavorski, J. M., and Ross, C. A. (1961). Antiserotonin antihistaminic properties of cyproheptadine. J. Pharmacol. exp. Ther., 131, 73-84.

Thomas, D. P., and Vane, J. R. (1967). 5-hydroxytryptamine in the circulation of the dog. Nature (Lond.), 216, 335-338.

Vane, J. R. (1969). The release and fate of vaso-active hormones in the circulation. Brit. J. Pharmacol., 35, 209-242.

Vroom, F. Q., Brown, R. E., Dempsey, H., and Richardson Hill, S. Jr. (1962). Studies on several possible antiserotonin compounds in a patient with the functioning carcinoid syndrome. Ann. intern. Med., 56, 941-945.

Wilkinson, M., Croft, P. B., and Urich, H. (1967). The remote effects of cancer on the nervous system. Proc. roy. Soc. Med., 60, 683-692. 